\title{
Diurnal dynamics of soil respiration and the influencing factors for three land-cover types in the hinterland of the Taklimakan Desert, China
}

\author{
YANG Fan ${ }^{1,2 *}$, ALI Mamtimin ${ }^{1,2}$, ZHENG Xinqian ${ }^{3}$, HE Qing ${ }^{1,2}$, YANG Xinghua ${ }^{1,2}$, HUO \\ Wen $^{1,2}$, LIANG Fengchao ${ }^{4}$, WANG Shaoming ${ }^{5}$ \\ ${ }^{1}$ Institute of Desert Meteorology, China Meteorological Administration, Urumqi 830002, China; \\ ${ }^{2}$ Taklimakan Desert Atmosphere and Environment Observation Experiment Station, Tazhong 841000, China; \\ ${ }^{3}$ Xinjiang Agro-Meteorological Observatory, Urumqi 830002, China; \\ ${ }^{4}$ Xinjiang Climate Center, Urumqi 830002, China; \\ ${ }^{5}$ Forestry Bureau of Bailongjiang, Lanzhou 730050, China
}

\begin{abstract}
Knowledge of soil respiration and the influencing factors in desert ecosystems is essential to understanding carbon dynamics and responses of biotic and abiotic processes in soils to climate change. In this study, soil respiration rate $\left(R_{s}\right)$ for three land-cover types (shifting sandy land, sandy land with straw checkerboard barriers, and shelter forest land) in the hinterland of the Taklimakan Desert was measured in May 2015 using an automated soil $\mathrm{CO}_{2}$ flux system. The effects of soil temperature $\left(T_{s}\right)$ and soil water content $\left(W_{s}\right)$ on $R_{s}$ were also analyzed. The results showed that $R_{s}$ values in shifting sandy land, sandy land with straw checkerboard barriers, and shelter forest land were all low and exhibited obvious diurnal fluctuations. The establishment of straw checkerboard barriers in sandy land had no significant effect on $R_{s}$, while the establishment of shelterbelts significantly increased $R_{s}$. Shifting sandy land and sandy land with straw checkerboard barriers were carbon sinks at night and early morning and were carbon sources in the daytime, while shelter forest land always acted as a carbon source during the whole day. The synergistic effect of $T_{s}$ and $W_{s}$ could better explain the diurnal dynamics in $R_{s}$ than single factor. In shifting sandy land and sandy land with straw checkerboard barriers, $W_{s}$ was identified as a limiting factor influencing the diurnal dynamics of $R_{s}$. Furthermore, a relatively strong hysteresis loop existed between $R_{s}$ and $T_{s}$. In contrast, in shelter forest land, $R_{s}$ was significantly influenced by $T_{s}$, and a relatively weaker hysteresis loop existed between $R_{s}$ and $W_{s}$.
\end{abstract}

Keywords: soil respiration; soil temperature; soil water content; hysteresis effect; Taklimakan Desert

Citation: YANG Fan, ALI Mamtimin, ZHENG Xinqian, HE Qing, YANG Xinghua, HUO Wen, LIANG Fengchao, WANG Shaoming. 2017. Diurnal dynamics of soil respiration and the influencing factors for three land-cover types in the hinterland of the Taklimakan Desert, China. Journal of Arid Land, 9(4): 568-579. doi: 10.1007/s40333-017-0060-0

\section{Introduction}

Soil is the main carbon pool in terrestrial ecosystems (Schlesinger and Andrews, 2000; Huang et al., 2007). The gross storage of organic carbon in soil is approximately $1395-2011 \mathrm{Pg}\left(1 \mathrm{Pg}=10^{15}\right.$ $\mathrm{g}$ ), accounting for $\sim 67 \%$ of the total carbon amount in terrestrial ecosystems (Jenkinson et al., 1991; Jin et al., 2009). The exchange process of carbon dioxide $\left(\mathrm{CO}_{2}\right)$ between the soil and atmosphere is referred to as soil respiration. Generally speaking, soil respiration includes four

*Corresponding author: YANG Fan (E-mail: yangfan309@yeah.net)

Received 2016-06-15; revised 2017-04-22; accepted 2017-05-09

(C) Xinjiang Institute of Ecology and Geography, Chinese Academy of Sciences, Science Press and Springer-Verlag Berlin Heidelberg 2017 
biotic processes (including plant root respiration, soil microbial respiration, soil animal respiration and soil organic matter decomposition) and many abiotic processes (such as chemical oxidation of carbonaceous matter, dissolution of carbonate, change of pressure gradients caused by wind and so on) (Singh and Gupta, 1977; Lou and Zhou, 2006; Jin et al., 2007; Feng et al., 2008). Soil respiration is the major route of carbon released from soil to atmosphere. At the global scale, the estimated amount of carbon released from soil to atmosphere is 50-75 Pg annually, which is higher than the net primary production (Jenkinson et al., 1991). Even slight variations of soil respiration can have far-reaching effects on the atmospheric $\mathrm{CO}_{2}$ concentration, and could generate a positive feedback on climate change (Rustad et al., 2000; Qi et al., 2006; Gao et al., 2012).

Desert, an important terrestrial ecosystem, is characterized by extreme drought, higher surface albedo, sandy underlying surface, and frequent sand-dust weather (Cable et al., 2011). Although desert ecosystem is generally low in soil organic carbon content, it plays an important role in soil carbon cycle (Liu et al., 2015). There are some recent researches on soil respiration in desert areas (e.g., Sierra, 2012; Jia et al., 2013; Zhang et al., 2015). A pervious study showed that soil respiration rate $\left(R_{s}\right)$ in desert areas is relatively high in fixed sandy land, relatively low in semi-fixed sandy and lowest in shifting sandy land (Li et al., 2008). $R_{s}$ in desert areas is affected by many factors, such as biomass of the phyto-community, soil organic carbon content, soil total nitrogen, soil temperature $\left(T_{s}\right)$, soil water content $\left(W_{s}\right)$, etc. (Sierra, 2012). $T_{s}$ and $W_{s}$ are the two most important factors influencing $R_{s}$ (Sierra, 2012) because $T_{s}$ and $W_{s}$ strongly modulate soil organic matter decomposition, root respiration, and microbial activity. It was reported that a significant hysteresis effect exists between $R_{s}$ and $T_{s}$ (Subke et al., 2003; Jia et al., 2013), and low levels of $W_{s}$ could increase the degree of hysteresis (Phillips et al., 2011; Wang et al., 2013). Thus, $W_{s}$ is of great importance in influencing $R_{s}$ in desert ecosystems (Cable et al., 2011; Zhang et al., 2015). Recent studies proposed that desert ecosystems, which have long been neglected in the studies of global carbon budget, exhibit strong downward fluxes into the ground and therefore might be a significant carbon sink (Jasoni et al., 2005; Stone, 2008; Wohlfahrt et al., 2008; Ma et al., 2014). This may be due to that highly saline-alkali soil can promote chemical reactions in the presence of moisture, such as the dissolution of calcium carbonate that causes atmospheric $\mathrm{CO}_{2}$ to be absorbed by the soil (Stone, 2008; Xie et al., 2009; Ma et al., 2013, 2014). Thomas and Hoon (2010) pointed out that soil could absorb atmospheric $\mathrm{CO}_{2}$ with assistance of soil microorganisms. In addition, studies on the response of soil respiration to precipitation indicated that precipitation in arid areas could strongly increase $R_{s}$ (Huang et al., 2007; Sponseller, 2007; Zhao et al., 2015). Soil respiration in desert areas is generally weak, thus it is easily ignored in related studies, limiting the needed in-depth understanding of soil respiration (Chen and Tian, 2005; Cable et al., 2011).

Desert covers an area of $0.7 \times 10^{6} \mathrm{~km}^{2}$ in China, with Taklimakan Desert being the largest one (accounting for about half of this area). In recent years, with the increase of human activities, a large number of straw checkerboard barriers and shelter forest belts were set up in the hinterland of the Taklimakan Desert to protect oil transportation and gas production from damage of drifting sands. As a result, the ground surface cover mainly consisting of continuous shifting sands was gradually changed and the regional biogeochemical cycles including carbon cycle were consequently affected.

In this study, $R_{s}, T_{s}$ and $W_{s}$ at 5-cm depth were synchronously monitored for three land-cover types (shifting sandy land, sandy land with straw checkerboard barriers, and shelter forest land) in the hinterland of the Taklimakan Desert. The objectives of this study were (1) to compare the diurnal dynamics of $R_{s}$ for the three land-cover types; (2) to discuss the effects of $T_{s}$ and $W_{s}$ on $R_{s}$; and (3) to explore the hysteresis effects between $R_{s}$ and $T_{s}$ and between $R_{s}$ and $W_{s}$.

\section{Materials and methods}

\subsection{Study area}

This study was conducted in the vicinity of the Taklimakan Desert Atmosphere and Environment 
Observing and Experimental Station $\left(38^{\circ} 58^{\prime} \mathrm{N}, 83^{\circ} 39^{\prime} \mathrm{E}\right.$; $1099 \mathrm{~m}$ a.s.1.), and the study area is situated in the Tazhong area (the hinterland) of the Taklimakan Desert, Xinjiang, Northwest China (Fig. 1). The distance from the station to the edge of the desert is about $229 \mathrm{~km}$. The study area is characterized by a warm-temperate arid desert climate with low precipitation (mean annual precipitation of $25.9 \mathrm{~mm}$ ) and high potential evaporation (annual potential evaporation of 3812.3 $\mathrm{mm}$ ). It should be noted that most of annual total precipitation occurs from May to August. The annual mean air temperature is $12.1^{\circ} \mathrm{C}$, the maximum air temperature ranges from $40.0^{\circ} \mathrm{C}$ to $46.0^{\circ} \mathrm{C}$, and the minimum air temperature ranges from $-32.6^{\circ} \mathrm{C}$ to $-20.0^{\circ} \mathrm{C}$. Natural vegetation coverage in the study area is relatively low. The ground surface is mainly covered by drifting sands. The prevailing wind comes from east and the annual mean wind velocity is $2.3 \mathrm{~m} / \mathrm{s}$. The mean occurrence of weather events with floating dust and blowing sand is more than $157 \mathrm{~d} / \mathrm{a}$, and the mean sandstorm occurrence is $16 \mathrm{~d} / \mathrm{a}$. The landscapes in the study area are mainly dominated by the inter-dune corridors and the linear and longitudinal dunes (direction of NNE-SSW or $\mathrm{NE}-\mathrm{SW}$; relative height of $40-50 \mathrm{~m}$ ).

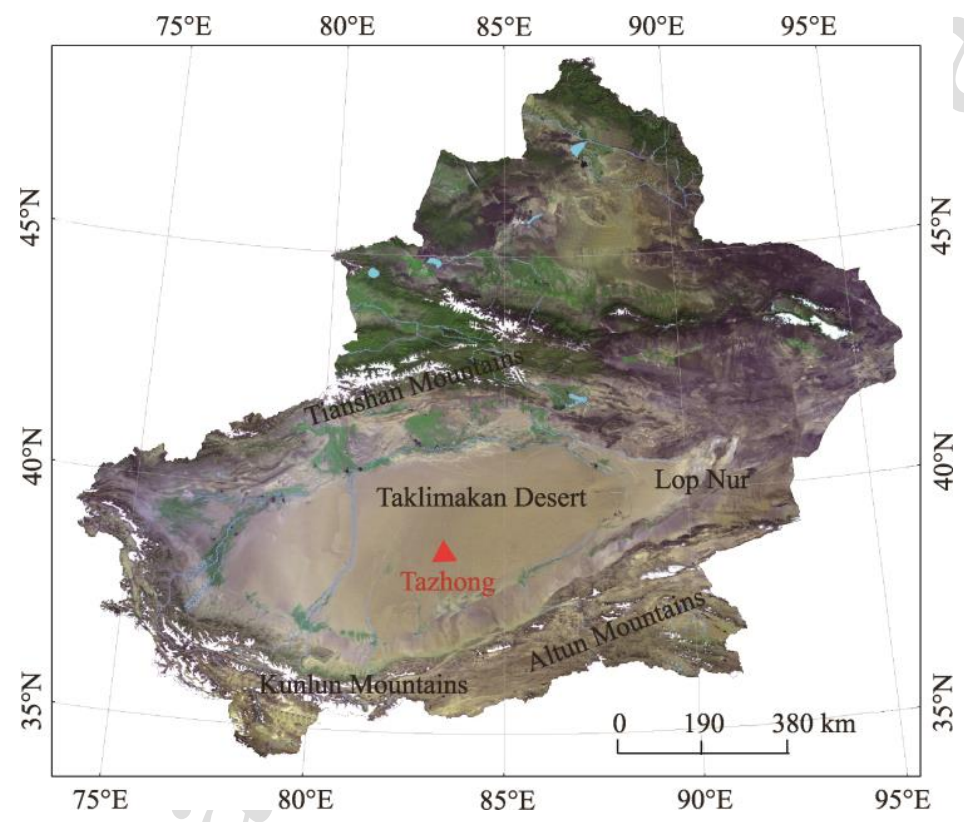

Fig. 1 Location of the Tazhong area (the hinterland) in the Taklimakan Desert

\subsection{Experiment methods}

Three land-cover types were selected: shifting sandy land, sandy land with straw checkerboard barriers, and shelter forest land (Fig. 2). For shifting sandy land, there was almost no vegetation at all. For sandy land with straw checkerboard barriers, the straw checkerboard barriers were made of reed that was placed (with half buried in the sand) in the shape of a checkerboard pattern (an area of $1.0 \mathrm{~m} \times 1.0 \mathrm{~m}$ for each checkerboard). The straw checkerboard barriers were installed in 2001. For shelter forest land, the shelter forest belts were dominated by Haloxylon ammodendron, Calligonum arborescens and Tamarix ramosissima planted in 2002. Since sand-dust weather occurs frequently in the hinterland of the Taklimakan Desert (i.e., Tazhong area), the straw checkerboard barriers, and shelter forest belts play important roles in wind prevention and sand stabilization. In May, the shelter forest experiences rapid leaf growth and canopy expansion, thus the protection effect is especially obvious.

For each land-cover type, three sampling plots with each area of $10 \mathrm{~m} \times 10 \mathrm{~m}$ were randomly selected. Soil respiration rate $\left(R_{S}\right)$ was measured with an automated soil $\mathrm{CO}_{2}$ flux system (Model LI-8100A fitted with a LI-8150 multiplexer, LI-COR, Nebraska, USA) during the periods of 1-8 May and 12-14 May, 2015. For each sampling plot, three polyvinyl chloride (PVC) cylindrical soil collars (cross section of $371.8 \mathrm{~cm}^{2}$ and height of $10 \mathrm{~cm}$ ) were separately embedded into the 
soil to a depth of $8 \mathrm{~cm}$. It should be noted that these PVC collars were installed 3 days before the measurements to avoid the influences of installation-resulted disturbance on $R_{s}$. After $72 \mathrm{~h}, R_{s}$ can be returned to the initial level before the installation of PVC collars. During the process of instrument parameter setting, the measurement time was prolonged to ensure the measurement accuracy. The stabilization time before gas extraction from the air chamber was set as $60 \mathrm{~s}$, and the measurement time of gas extraction and the stabilization time after measurements were set as 150 and $30 \mathrm{~s}$, respectively. For each chamber, measurements were conducted at 30-min intervals. Meanwhile, for each land-cover type, soil temperature $\left(T_{s}\right)$ and soil water content $\left(W_{s}\right)$ at 5 -cm depth were measured near the chambers using the 8150-203 soil temperature sensor and EC-5 soil moisture sensor (LI-COR, Nebraska, USA), respectively. After the measurements of $R_{s}$, the 0-10-cm topsoil inside the PVC collars was collected to analyze its physical and chemical properties. Soil total salt, organic carbon, total nitrogen, and $\mathrm{pH}$ were measured by the residue-drying method, potassium dichromate-volumetric method, AA3 continuous flow analytical system and $\mathrm{pH}-3 \mathrm{C} \mathrm{pH}$ Meter (Bao, 2000), respectively. Soil physical and chemical properties in the topsoil layer for the three land-cover types are presented in Table 1.
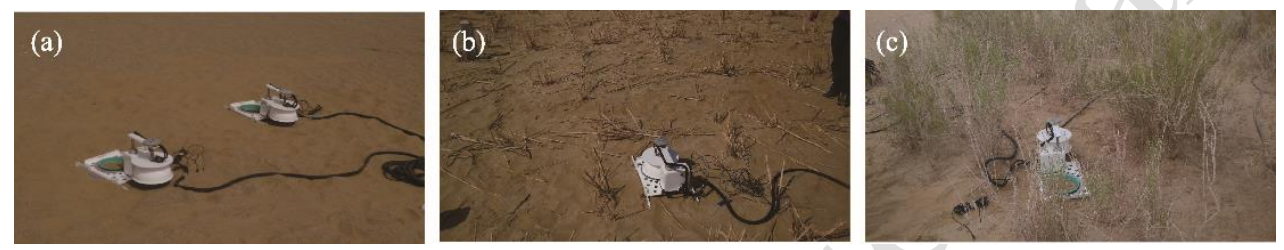

Fig. 2 Layout of the three land-cover types and soil $\mathrm{CO}_{2}$ flux monitoring equipment. (a), shifting sandy land; (b), sandy land with straw checkerboard barriers; (c), shelter forest land.

Table 1 Soil physical and chemical properties in the $0-10-\mathrm{cm}$ topsoil layer in shifting sandy land, sandy land with straw checkerboard barriers, and shelter forest land

\begin{tabular}{lccccccc}
\hline Land-cover type & Depth $(\mathrm{cm})$ & Soil type & STS $(\mathrm{g} / \mathrm{kg})$ & SOC $(\mathrm{g} / \mathrm{kg})$ & STN $(\mathrm{g} / \mathrm{kg})$ & $\mathrm{C} / \mathrm{N}$ & $\mathrm{pH}$ \\
\hline \multirow{2}{*}{ Shifting sandy land } & $0-5$ & Sand & $3.45 \pm 0.35$ & $0.56 \pm 0.12$ & $0.06 \pm 0.01$ & $9.85 \pm 0.83$ & $7.33 \pm 0.02$ \\
& $5-10$ & Sand & $9.64 \pm 1.10$ & $0.63 \pm 0.03$ & $0.09 \pm 0.02$ & $7.66 \pm 1.58$ & $7.30 \pm 0.04$ \\
Sandy land with straw & $0-5$ & Sand & $1.26 \pm 0.06$ & $0.89 \pm 0.01$ & $0.09 \pm 0.01$ & $9.73 \pm 1.74$ & $7.33 \pm 0.08$ \\
checkerboard barriers & $5-10$ & Sand & $1.32 \pm 0.09$ & $0.90 \pm 0.05$ & $0.10 \pm 0.03$ & $9.10 \pm 1.81$ & $7.38 \pm 0.74$ \\
& $0-5$ & Sand & $1.28 \pm 0.04$ & $0.90 \pm 0.08$ & $0.07 \pm 0.03$ & $13.60 \pm 3.65$ & $8.28 \pm 0.44$ \\
Shelter forest land & $5-10$ & Sand & $2.04 \pm 0.08$ & $1.15 \pm 0.17$ & $0.13 \pm 0.04$ & $9.31 \pm 1.57$ & $7.43 \pm 0.13$ \\
\hline
\end{tabular}

Note: STS, soil total salt; SOC, soil organic carbon; STN, soil total nitrogen; C/N, ratio of SOC to STN. Mean \pm SD.

It should be noted that under low $W_{s}$ conditions in the study area, the EC-5 soil moisture sensors matched by an automatic soil $\mathrm{CO}_{2}$ flux system can easily cause measurement errors. Therefore, it is necessary to correct the $W_{s}$ measurements (using the EC-5 soil moisture sensors) by the traditional drying method. In this study, we conducted a supplementary experiment in November 2016 to correct the $W_{s}$ measured using the EC-5 soil moisture sensors in the field. Specifically, samples of topsoil layer $(0-10 \mathrm{~cm})$ from shifting sandy land were divided into three portions and were dissolved into 0,180 , and $270 \mathrm{~mL}$ of distilled water, respectively. After efficient stirring, they were moved into three same cylindrical boxes to form three soil moisture gradients. Then, the three cylindrical boxes were placed into an artificial climatic chest (Model HP1500GS, Ruihua Inc., Wuhan, China), with air temperature maintaining at $30^{\circ} \mathrm{C}$, air humidity at 20\%, and illumination at level 2. Three EC-5 soil moisture sensors were then embedded into the boxes at a burial depth of $5 \mathrm{~cm}$, and continuously recorded the $W_{s}$ changes. Meanwhile, $W_{s}$ was measured by the traditional drying method in the same layer, i.e., 5-cm depth. The results are shown in Figure 3. The results of two measuring methods exhibited a certain similarity. It should be noted that although the EC-5 soil moisture sensor can reflect variations in $W_{s}$ with time, a certain level of discrepancy in values between the two methods still exists: the lower the $W_{s}$, the larger the discrepancy. In the treatment of added $0 \mathrm{~mL}$ of distilled water, the average $W_{s}$ value 
measured by the EC-5 soil moisture sensors was 20 times that by the drying method. Thus, 20 was regarded as the correction coefficient of the $W_{s}$ measured by the EC-5 soil moisture sensors in the field.

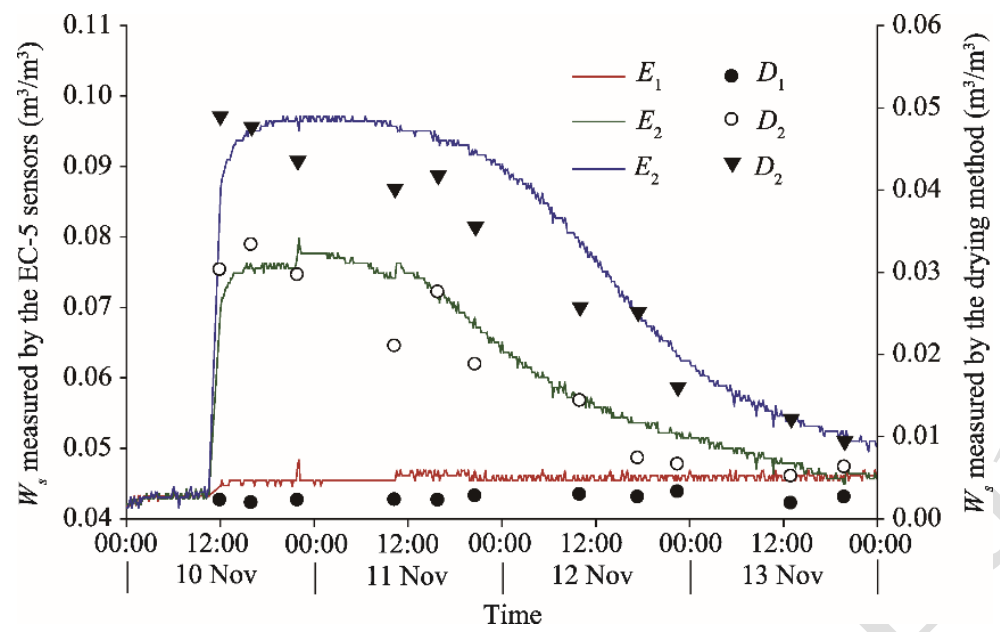

Fig. 3 Comparison of $W_{s}$ (soil water content) measured by the EC-5 soil moisture sensors and by the traditional drying method at three soil moisture gradients. The supplementary experiment was conducted in November 2016 to correct the $W_{s}$ measured using the EC-5 soil moisture sensors in the field. $E_{1}, E_{2}$, and $E_{3}$ represent that $W_{s}$ was measured by the EC-5 soil moisture sensors in the treatments of added 0,180 , and $270 \mathrm{~mL}$ of distilled water, respectively; and $D_{1}, D_{2}$, and $D_{3}$ represent that $W_{s}$ was measured by the drying method in the treatments of added 0,180 , and $270 \mathrm{~mL}$ of distilled water, respectively.

\subsection{Data analysis}

In this study, statistical analysis was performed using SPSS 16.0 and Sigmaplot 12.5. Correlation analysis and partial correlation analysis were used to examine the relationships between $R_{s}$ $\left(\mu \mathrm{mol} /\left(\mathrm{m}^{2} \cdot \mathrm{s}\right)\right), T_{s}\left({ }^{\circ} \mathrm{C}\right)$ and $W_{s}\left(\mathrm{~m}^{3} / \mathrm{m}^{3}\right)$ at $5-\mathrm{cm}$ soil depth for the selected three land-cover types. Regression analysis was used to determine the effects of $T_{s}$ and $W_{s}$ on $R_{s}$. The following three types of non-linear functions were used to analyze the synergistic effect of $T_{s}$ and $W_{s}$ on $R_{s}$ :

$$
\begin{gathered}
R_{s}=a+b \times T_{s}+c \times W_{s}, \\
R_{s}=a+b \times T_{s}+c \times W_{s}+d \times T_{s} \times W_{s}, \\
R_{s}=a \times T_{s}^{\mathrm{b}} \times W_{s}^{\mathrm{c}},
\end{gathered}
$$

where, $a$, also known as basal respiration rate, is the soil respiration rate when $T_{s}$ and $W_{s}$ are both equal to $0\left(\mu \mathrm{mol} /\left(\mathrm{m}^{2} \cdot \mathrm{s}\right) ; b\right.$ and $c$ are reaction coefficients of $T_{s}$ and $W_{s}$, respectively; and $d$ is the coefficient of internal interaction between $T_{s}$ and $W_{s}$.

\section{Results}

\subsection{Diurnal dynamics of $\boldsymbol{R}_{s}$}

$R_{s}$ in shifting sandy land, sandy land with straw checkerboard barriers, and shelter forest land all displayed obvious diurnal fluctuations. $R_{S}$ in shifting sandy land and sandy land with straw checkerboard barriers exhibited similar diurnal dynamics (unimodal curves) with low values (Fig. 4). In comparison, $R_{s}$ values in shelter forest land were high and the diurnal dynamic was different from those in the other two land-cover types. Specifically, diurnal $R_{s}$ values in shifting sandy land and sandy land with straw checkerboard barriers ranged from -0.10 to $0.22 \mu \mathrm{mol} /\left(\mathrm{m}^{2} \cdot \mathrm{s}\right.$ ) (average of $8.9 \times 10^{-3} \mu \mathrm{mol} /\left(\mathrm{m}^{2} \cdot \mathrm{s}\right)$ ) and from -0.06 to $0.18 \mu \mathrm{mol} /\left(\mathrm{m}^{2} \cdot \mathrm{s}\right)$ (average of $24.4 \times 10^{-3} \mu \mathrm{mol} /\left(\mathrm{m}^{2} \cdot \mathrm{s}\right)$ ), respectively. Diurnal $R_{s}$ values in shelter forest land ranged from 0.54 to $0.85 \mu \mathrm{mol} /\left(\mathrm{m}^{2} \cdot \mathrm{s}\right)$, with an average of $0.693 \mu \mathrm{mol} /\left(\mathrm{m}^{2} \cdot \mathrm{s}\right)$, being 77.9 and 28.4 times larger than those in shifting sandy land and sandy land with straw checkerboard barriers, respectively. The diurnal $R_{S}$ values in shifting sandy land were consistently negative from 17:00 (Beijing time) on the preceding day to 
08:00 on the succeeding day and the diurnal $R_{s}$ values in sandy land with straw checkerboard barriers were consistently negative from 17:00 on the preceding day to 06:00 on the succeeding day, indicating that soil absorbed $\mathrm{CO}_{2}$ from the atmosphere during this negative-value period. After this negative-value period, $R_{s}$ values became positive with the maximum values both occurred at 11:00 $\left(0.22\right.$ and $0.18 \mu \mathrm{mol} /\left(\mathrm{m}^{2} \cdot \mathrm{s}\right)$, respectively) and then decreased rapidly. For shelter forest land, diurnal $R_{S}$ values were all positive throughout the day, suggesting that this land-cover type always maintained in a state of soil $\mathrm{CO}_{2}$ release. The diurnal maximum of $R_{s}$ for shelter forest land was delayed by $3 \mathrm{~h}$ with respect to those for the other two land-cover types. The aforementioned results show that, in the hinterland of the Taklimakan Desert, the establishment of straw checkerboard barriers in sandy land had no significant influence on $R_{s}$, while the establishment of shelter belts significantly increased $R_{s}$.

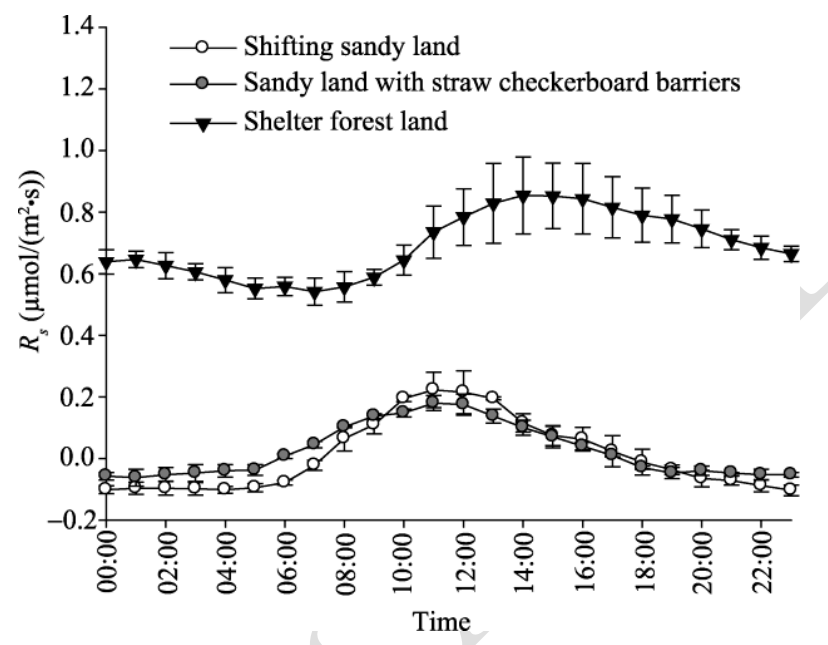

Fig. 4 Diurnal dynamics of $R_{s}$ (soil respiration rate) in shifting sandy land, sandy land with straw checkerboard barriers, and shelter forest land. Bars denote standard deviations.

\subsection{Effects of $T_{s}$ on $R_{s}$}

Correlation analyses and regression analyses between $R_{s}$ and $T_{s}$ in shifting sandy land, sandy land with straw checkerboard barriers, and shelter forest land are shown in Figure 5. A significant positive correlation was found between $R_{s}$ and $T_{s}$ in shelter forest land ( $r=0.983, P<0.001$; Fig. $5 \mathrm{c})$. The correlation between $R_{s}$ and $T_{s}$ in shifting sandy land was lower $(r=0.757, P<0.001)$ than that in shelter forest land. The maximum $R_{s}$ appeared earlier than the maximum $T_{s}$, presenting a clear hysteresis phenomenon (Fig. 5a). For the three land-cover types, the hysteresis phenomenon in sandy land with straw checkerboard barriers was the most obvious. In addition, there was a negative correlation between $R_{s}$ and $T_{s}(r=-0.225, P=0.291)$ for in sandy land with straw checkerboard barriers (Fig. 5b). Using artificial elimination of the hysteresis in shifting sandy land and sandy land with straw checkerboard barriers (i.e., advancing $T_{s}$ by 2 and $3 \mathrm{~h}$, respectively), the correlation coefficients between $R_{s}$ and $T_{s}$ increased to $0.957(P<0.001)$ and $0.971(P<0.001)$, respectively.

For shelter forest land, a linear regression model was best for fitting the relationship between $R_{S}$ and $T_{s}\left(R^{2}=0.849, P<0.0001\right.$; Fig. 5f $)$. For shifting sandy land and sandy land with straw checkerboard barriers, however, the linear relationship between $R_{s}$ and $T_{s}$ was weak (Figs. $5 \mathrm{~d}$ and e, respectively). An obvious clockwise loop was found when plotting $R_{s}$ against $T_{s}$, especially for sandy land with straw checkerboard barriers. In the clockwise loop, $R_{s}$ values in the increasing stage were higher than $T_{s}$ values in the decreasing stage. According to the distribution of the scatter points, the segmentation fitting was carried out with 05:00 and 13:00 as the boundaries. The fitting results are listed in Table 2. In general, from shelter forest land through shifting sandy land and to sandy land with straw checkerboard barriers, the consistency between $R_{s}$ and $T_{s}$ gradually decreased. However, with respect to $R_{s}$, the hysteresis effect of $T_{s}$ was gradually 
intensified, that is, the 'hysteresis loop' was most obvious in sandy land with straw checkerboard barriers.
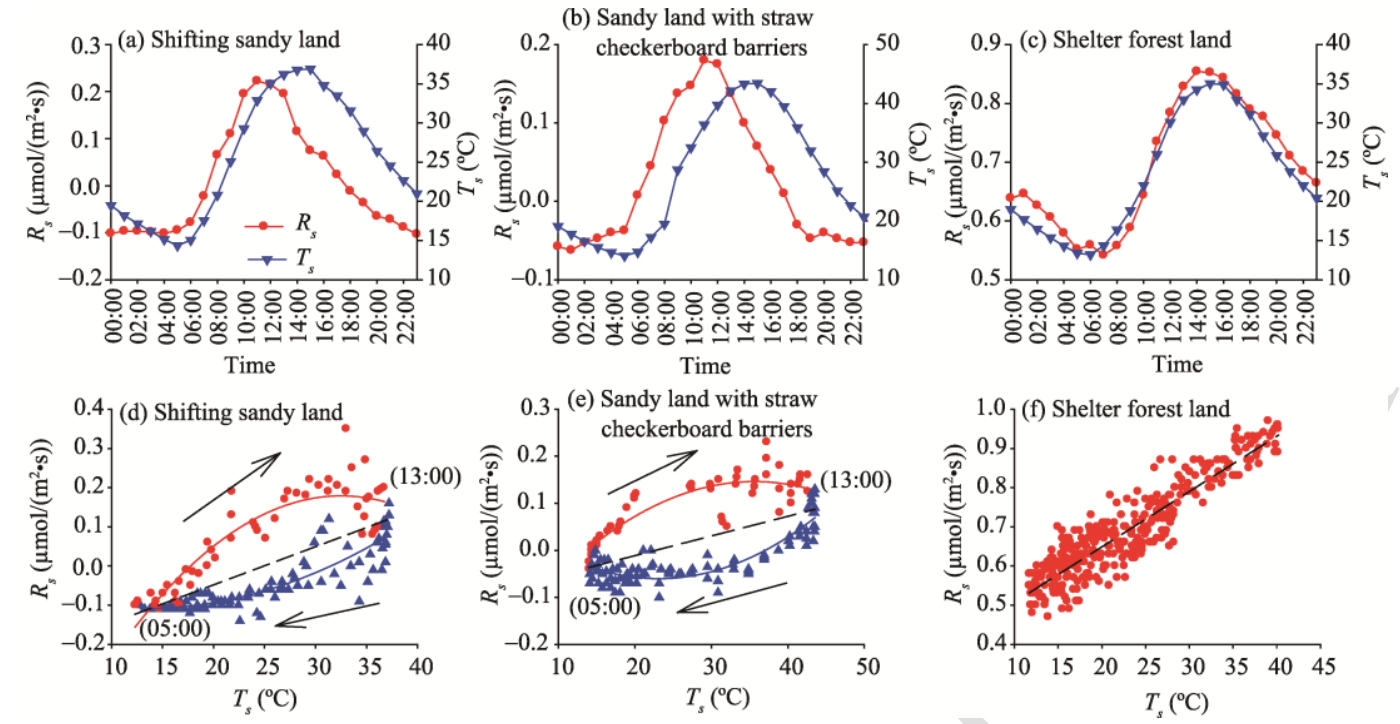

Fig. 5 Correlation analyses (a, b, c) and regression analyses (d, e, f) between $R_{s}$ and $T_{s}$ (soil temperature) at 5-cm depth in shifting sandy land, sandy land with straw checkerboard barriers, and shelter forest land. Arrow indicates the direction of the hysteresis effect.

Table 2 Regression equations between $R_{s}$ (soil respiration rate) and $T_{s}$ (soil temperature) at 5-cm depth for shifting sandy land, sandy land with straw checkerboard barriers, and shelter forest land

\begin{tabular}{llllll}
\hline Land-cover type & Stage & Regression equation & $R^{2}$ & $F$ & $P$ \\
\hline Shifting sandy land & Synthesis stage & $R_{s}=0.010 T_{s}-0.243$ & 0.484 & 134.080 & $<0.0001$ \\
& Increasing stage & $R_{s}=-0.688+0.053 T_{s}-8 \times 10^{-4} T_{s}^{2}$ & 0.817 & 113.893 & $<0.0001$ \\
& Decreasing stage & $R_{s}=-0.052-9 \times 10^{-3} T_{s}+3 \times 10^{-4} T_{s}^{2}$ & 0.766 & 143.801 & $<0.0001$ \\
Sandy land with straw & Synthesis stage & $R_{s}=0.004 T_{s}-0.095$ & 0.307 & 62.825 & $<0.0001$ \\
checkerboard barriers & Increasing stage & $R_{s}=-0.239+0.022 T_{s}-3 \times 10^{-4} T_{s}^{2}$ & 0.731 & 63.766 & $<0.0001$ \\
& Decreasing stage & $R_{s}=0.106-0.014 T_{s}+3 \times 10^{-4} T_{s}^{2}$ & 0.772 & 154.031 & $<0.0001$ \\
Shelter forest land & Synthesis stage & $R_{s}=0.014 T_{s}+0.367$ & 0.849 & 1914.429 & $<0.0001$ \\
\hline
\end{tabular}

Note: $R^{2}$ is the goodness-of-fit of the regression equation; $F$ is the $F$-statistic of the fit; and $P$ is the significance level of the $F$-test.

\subsection{Effects of $W_{s}$ on $R_{s}$}

$W_{s}$ is another significant factor affecting $R_{s}$. Correlation analyses and regression analyses between $R_{s}$ and $W_{s}$ are shown in Figure 6. There were obvious diurnal fluctuations for both $R_{s}$ and $W_{s}$ (Figs. 6a-c). Generally speaking, the shifting sandy land had the best consistency between $R_{s}$ and $W_{s}$, showing a significant positive correlation $(r=0.935, P<0.001)$. The correlation between $R_{s}$ and $W_{s}$ in shifting sandy land with straw checkerboard barriers was slightly lower $(r=0.901, P<0.001)$ than that in shifting sandy land. In shelter forest land, $R_{s}$ and $W_{s}$ also presented a hysteresis phenomenon but was different from the hysteresis between $R_{s}$ and $T_{s}$. That is, the maximum $R_{s}$ appeared later than the maximum $W_{s}(r=0.727, P<0.001)$. After eliminating the hysteresis between $R_{s}$ and $W_{s}$, the coefficient was increased to $0.959(P<0.001)$. All in all, even a slight variation in $W_{s}$ could result in a considerable change in $R_{s}$.

For shifting sandy land and sandy land with straw checkerboard barriers, the exponential equation could better describe the relationship between $R_{s}$ and $W_{s}$ (Figs. 6d and e; Table 3), with $R^{2}$ being $0.822 \quad(P<0.001)$ and $0.691 \quad(P<0.001)$, respectively. For shelter forest land, the regression distribution of $R_{s}$ and $W_{s}$ showed a relatively weak circular hysteresis (Fig. 6f). This hysteresis loop was counterclockwise, indicating that the phase of $R_{s}$ lagged behind that of $W_{s}$. 


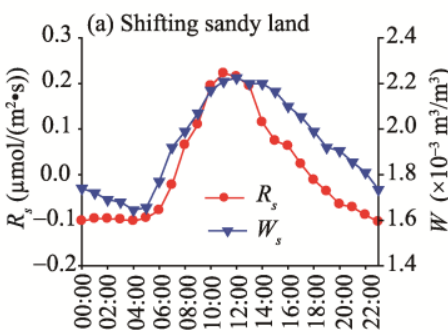

Time

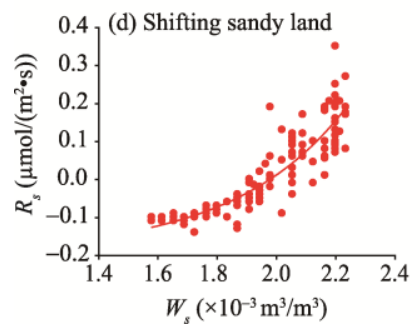

(b) Sandy land with straw
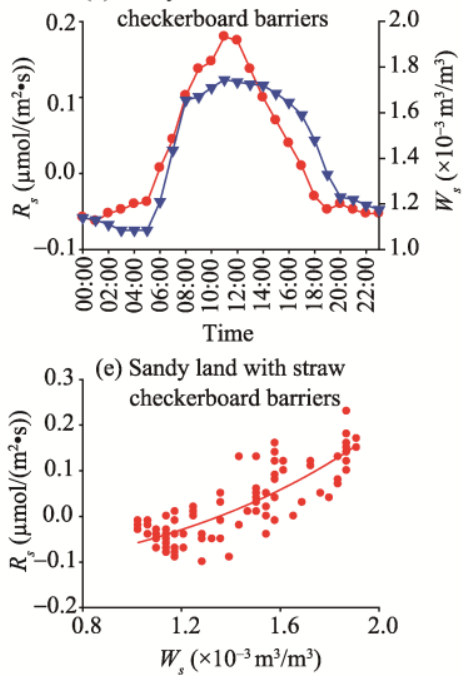

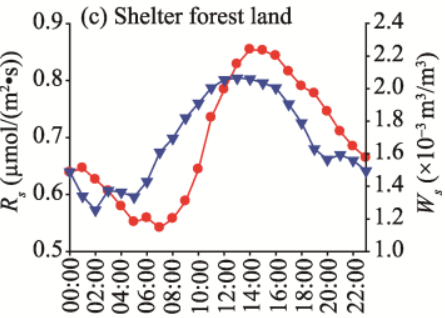

Time

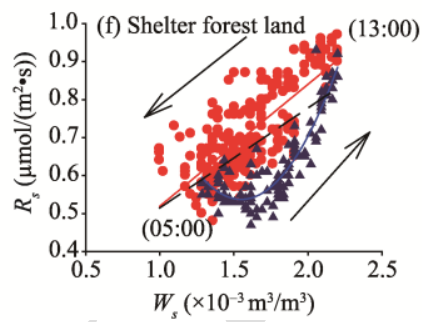

Fig. 6 Correlation analyses (a, b, c) and regression analyses (d, e, f) between $R_{s}$ and $W_{s}$ (soil water content) at $5-\mathrm{cm}$ depth in shifting sandy land, sandy land with straw checkerboard barriers, and shelter forest land. Arrow indicates the direction of the hysteresis effect.

Table 3 Regression equations between $R_{s}$ and $W_{s}$ (soil water content) at 5-cm depth for shifting sandy land, sandy land with straw checkerboard barriers, and shelter forest land

\begin{tabular}{llllll}
\hline Land-cover type & Stage & Regression equation & $R^{2}$ & $F$ & $P$ \\
\hline Shifting sandy land & Synthesis stage & $R_{s}=-0.193+0.001 \mathrm{e}^{2648.93 W_{s}}$ & 0.822 & 327.386 & $<0.0001$ \\
Sandy land with straw & Synthesis stage & $R_{s}=-0.200+0.050 \mathrm{e}^{1036.8 W_{s}}$ & 0.691 & 103.789 & $<0.0001$ \\
checkerboard barriers & Synthesis stage & $R_{s}=262.70 W_{s}+0.250$ & 0.377 & 205.870 & $<0.0001$ \\
Shelter forest land & Increasing stage & $R_{s}=2.514-2550.20 W_{s}+8.223 \times 10^{5} W_{s}^{2}$ & 0.837 & 260.985 & $<0.0001$ \\
& Declining stage & $R_{s}=320.71 W_{s}+0.199$ & 0.600 & 352.986 & $<0.0001$ \\
\hline
\end{tabular}

\subsection{Synergistic effect of $T_{s}$ and $W_{s}$ on $R_{s}$}

In the model that combines $T_{s}$ and $W_{s}$, Equations 1-3 (in Section 2.3) were all used to analyze the synergistic effect of $T_{s}$ and $W_{s}$ on $R_{\mathrm{s}}$. As shown in Table 4, these equations could well describe the responses of $R_{s}$ to variations in $T_{s}$ and $W_{s}$ for all the three land-cover types $(P<0.01)$, with an exception of Equation 3, which failed to explain the synergistic effect of $T_{s}$ and $W_{s}$ on $R_{\mathrm{s}}$ in shifting sandy land and sandy land with straw checkerboard barriers. The result indicates that $R_{s}$ in the study area was affected by $T_{s}$ and $W_{s}$ together. In general, Equations 1 and 2 could better explain the diurnal dynamics of $R_{\mathrm{s}}$ for the three land-cover types. The combination of $T_{s}$ and $W_{s}$ can explain more than $88 \%$ of the total variation of $R_{s}$.

\section{Discussion}

$R_{s}$ values in shifting sandy land, sandy land with straw checkerboard barriers, and shelter forest land in the hinterland of the Taklimakan Desert were significantly lower than those in the other land-cover types, e.g., deciduous broadleaf forest, evergreen needle leaf forest, grassland, and woodland/savanna (Hibbard et al., 2005). Lower $R_{s}$ values in the study area were mainly caused by extreme climate conditions (low precipitation, high evaporation, and frequent sand-wind weather), relatively few soil microorganisms and animals, and scarce vegetation (low root respiration). Generally speaking, the establishment of straw checkerboard barriers in sandy land in the hinterland of the Taklimakan Desert had little effect on $R_{s}$, while the establishment of shelterbelts significantly increased $R_{s}$. The establishment of shelterbelts not only increased the plant root respiration, but also changed the soil physical and chemical properties, providing 
Table 4 Multiple regression equations and curve fitting analyses for $R_{s}$ with $T_{s}$ and $W_{s}$ for shifting sandy land, sandy land with straw checkerboard barriers, and shelter forest land

\begin{tabular}{|c|c|c|c|c|}
\hline Land cover type & Equation type & Fitted equation & $R^{2}$ & $F$ \\
\hline \multirow[t]{3}{*}{ Shifting sandy land } & (1) & $R_{s}=-1.308-0.007 T_{s}+768.723 W_{s}$ & $0.913^{* *}$ & 110.785 \\
\hline & $(2)$ & $R_{s}=-0.476-0.042 T_{s}+337.740 W_{s}+17.993 T_{s} W_{s}$ & $0.946^{* *}$ & 115.747 \\
\hline & (3) & Failed & & \\
\hline Sandy land with straw & (1) & $R_{s}=-0.458-0.004 T_{s}+415.493 W_{s}$ & $0.881^{* *}$ & 77.504 \\
\hline \multirow[t]{2}{*}{ checkerboard barriers } & (2) & $R_{s}=-0.117-0.019 T_{s}+179.083 W_{s}+9.794 T_{s} W_{s}$ & $0.923^{* *}$ & 80.095 \\
\hline & (3) & Failed & & \\
\hline \multirow[t]{3}{*}{ Shelter forest land } & (1) & $R_{s}=0.469+0.017 T_{s}-96.619 W_{s}$ & $0.986^{* *}$ & 721.559 \\
\hline & (2) & $R_{s}=0.579+0.011 T_{s}-161.574 W_{s}+2.929 T_{s} W_{s}$ & $0.987^{* *}$ & 523.033 \\
\hline & (3) & $R_{s}=0.033 T_{s}^{0.541} W_{s}^{-0.211}$ & $0.979^{* *}$ & 498.181 \\
\hline
\end{tabular}

Note: ${ }^{* *}$ indicates significant difference at $P<0.01$ level (two-tailed). The types of equation can be found in Section 2.3 .

beneficial conditions to the activities of soil microorganisms and animals and resulting in the increase of $R_{s}$. Similar to the results in other studies (Huang et al., 2007; Zhang et al., 2007; Wang et al., 2013), $R_{s}$ values for the three land-cover types all showed obvious diurnal fluctuations. It is noteworthy that the phase of diurnal change in $R_{s}$ for shelter forest land lagged behind than those for shifting sandy land and sandy land with straw checkerboard barriers. Both $T_{s}$ and $W_{s}$ showed hysteresis with $R_{s}$ in shelter forest land. This may be due to that the increased vegetation cover reduced the sensitivity of $T_{s}$ and $W_{s}$ to the variations in external environmental conditions.

For shifting sandy land and sandy land with straw checkerboard barriers, soil absorbed $\mathrm{CO}_{2}$ from the atmosphere at night and early morning and released $\mathrm{CO}_{2}$ into the atmosphere during the daytime, being consistent with those previously reported. For examples, the saline-alkali soil of the Gurbantunggut Desert in northern Xinjiang of China was subjected to potential chemical reactions with the action of soil moisture at night and early morning and then calcium carbonate in the soil was dissolved, promoting soil $\mathrm{CO}_{2}$ absorption (Stone, 2008; Xie et al., 2009). By sterilization control experiment, Wang et al. (2013a, b) illustrated that soil $\mathrm{CO}_{2}$ absorption was a comprehensive reflection of soil organic and inorganic $\mathrm{CO}_{2}$ fluxes and that the absorption of inorganic carbon at night was one of the main reasons for forming carbon sink in the deserts. They also found that the saline-alkali soil with high $\mathrm{pH}$ value and low temperature could promote soil $\mathrm{CO}_{2}$ absorption. Similarly, Ma et al. (2013) showed that in the Gurbantunggut Desert, inorganic processes could cause the negative soil $\mathrm{CO}_{2}$ flux, forming a carbon sink. Due to the fact that soil is quite dry in the desert ecosystems, all soil $\mathrm{CO}_{2}$ fluxes may originate from inorganic processes (which are affected by $T_{s}$ ). Furthermore, soil $\mathrm{pH}$ controls the amplitude of variation of soil $\mathrm{CO}_{2}$ flux to some extent. The soil in the hinterland of the Taklimakan Desert exhibited high salinity and high alkali characteristics, with soil $\mathrm{pH}$ in the range of 8.66-9.54 (average of 9.22) and total salinity content in the range of $0.27 \%-1.86 \%$ (average of $0.78 \%$ ). Therefore, we speculate that under high soil salinity and alkali conditions, soil inorganic carbon process is one of the main reasons to form carbon sink in the Taklimakan Desert.

It was previously reported that $T_{s}, W_{s}$ and the combination of $T_{s}$ and $W_{s}$ are the main driving factors influencing $R_{s}$ in arid and semi-arid regions (e.g., Zhang et al., 2007; Wang et al., 2012). In the hinterland of the Taklimakan Desert, a robust linear relationship between $R_{s}$ and $T_{s}$ was found in shelter forest land, and a segmentation fitting was observed in shifting sandy land and sandy land with straw checkerboard barriers, being similar to those for the same land-use types in the northern margin of the Taklimakan Desert (Yang et al., 2015) and being dissimilar to the results for other land-use types (Huang et al., 2007; Zhang et al., 2007). However, all these observations indicated that $T_{s}$ was an important factor influencing $R_{s}$, and the responses of $R_{s}$ to $T_{s}$ were different in different land-use types. In desert ecosystems, $W_{s}$ is another major influencing factor on soil respiration processes (Oechel et al., 2000; Zhou et al., 2009). In the hinterland of the Taklimakan Desert, exponential relationships between $R_{s}$ and $W_{s}$ were found in shifting sandy land and sandy land with straw checkerboard barriers, while hysteresis phenomenon was observed 
in shelter forest land. The synergistic effect of $T_{s}$ and $W_{s}$ could better explain the diurnal dynamics of $R_{s}$.

In this study, regression analyses of $R_{S}$ and environmental factors $\left(T_{s}\right.$ and $\left.W_{s}\right)$ showed that obvious circular hysteresis loop existed between $R_{s}$ and environmental factors. The hysteresis loop was clockwise when the phase of $R_{s}$ was advanced relative to the environmental factor. The hysteresis loop was counterclockwise when the phase of $R_{s}$ was lagged behind the environmental factor. This phenomenon was also found in the Xiaotang area of the Taklimakan Desert (Yang et al., 2015) and the Yanchi area of the Mu Us Desert (Wang et al., 2013). According to the partial correlation analysis of the relationships between $R_{s}$ and $T_{s}$ and between $R_{s}$ and $W_{s}, R_{s}$ and $T_{s}$ was negatively correlated when $W_{s}$ was the control variable (Table 5). In contrast, $R_{s}$ and $W_{s}$ was positively correlated when $T_{s}$ was the control variable. $W_{s}$ in the hinterland of the Taklimakan Desert was low and was likely the limiting factor of soil respiration in shifting sandy land and sandy land with straw checkerboard barriers. The response of $R_{s}$ to the diurnal variations in $W_{s}$ was more direct and sensitive, and the corresponding regression relationship exhibited an exponential function. For shelter forest land, plant root was the main contributor to soil respiration, and therefore the diurnal variations of $W_{s}$ in short periods did not significantly affect $R_{s}$. Accordingly, the hysteresis loop between $R_{s}$ and $W_{s}$ was also relatively vague. The response of $R_{s}$ to the diurnal variations of $T_{s}$ was more direct in shelter forest land.

Table 5 Partial correlation analyses of $R_{s}, T_{s}$ and $W_{s}$ for shifting sandy land, sandy land with straw checkerboard barriers, and shelter forest land

\begin{tabular}{|c|c|c|c|c|}
\hline \multirow{2}{*}{ Variable } & \multirow{2}{*}{ Control variable } & \multirow{2}{*}{ Land-cover type } & \multicolumn{2}{|c|}{$r$} \\
\hline & & & $T_{s}$ & $W_{s}$ \\
\hline \multirow{6}{*}{$R_{s}$} & \multirow{4}{*}{$T_{s}$} & Shifting sandy land & & 0.893 \\
\hline & & Sandy land with straw checkerboard barriers & & 0.906 \\
\hline & & Shelter forest land & & -0.760 \\
\hline & & Shifting sandy land & -0.567 & \\
\hline & \multirow[t]{2}{*}{$W_{s}$} & Sandy land with straw checkerboard barriers & -0.613 & \\
\hline & & Shelter forest land & 0.985 & \\
\hline
\end{tabular}

\section{Conclusions}

In the hinterland of the Taklimakan Desert, we found that there were relatively obvious diurnal dynamics of $R_{s}, T_{s}$ and $W_{s}$, and also robust regression relationships between $R_{s}$ and $T_{s}$ and between $R_{s}$ and $W_{s}$ at 5 -cm depth for shifting sandy land, sandy land with straw checkerboard barriers, and shelter forest land. The synergistic effect of $T_{s}$ and $W_{s}$ could better explain the diurnal dynamics of $R_{s}$. The establishment of straw checkerboard barriers in sandy land had no significant effect on $R_{s}$, while the establishment of shelterbelts significantly increased $R_{s}$ and slowed or smoothed the responses of $R_{s}$ to the variations in $T_{s}$ and $W_{s}$. Shifting sandy land and sandy land with straw checkerboard barriers acted as carbon sinks at night and early morning and acted as carbon sources in the daytime. However, shelter forest land acted as a carbon source during whole day because $R_{s}$ was always in a state of soil $\mathrm{CO}_{2}$ release.

\section{Acknowledgements}

This study was funded by the National Natural Science Foundation of China (41175140) and the National Department of Public Benefit (Meteorology) Research Foundation (GYHY201306066).

\section{References}

Bao S D. 2000. Soil and Agricultural Chemistry Analysis ( $3^{\text {rd }}$ ed.). Beijing: China Agriculture Publishing Company, 30-187. (in Chinese)

Cable J M, Ogle K, Lucas R W, et al. 2011. The temperature responses of soil respiration in deserts: a seven desert synthesis. 
Biogeochemistry, 103(1-3): 71-90.

Chen H, Tian H Q. 2005. Does a general temperature-dependent $\mathrm{Q}_{10}$ model of soil respiration exist at Biome and global scale? Journal of Integrative Plant Biology, 47(11): 1288-1302.

Feng C Y, Lü S H, Gao J X, et al. 2008. Soil respiration characteristics of different vegetation types in the mountain areas of north China. Journal of Beijing Forestry University, 30(2): 20-26. (in Chinese)

Gao Y H, Liu L C, Jia R L, et al. 2012. Soil respiration patterns during restoration of vegetation in the Shapotou area, Northern China. Acta Ecologica Sinica, 32(8): 2474-2482. (in Chinese)

Hibbard K A, Law B E, Reichstein M, et al. 2005. An analysis of soil respiration across northern hemisphere temperate ecosystems. Biogeochemistry, 73(1): 29-70.

Huang X, Li W H, Chen Y N, et al. 2007. Soil respiration of desert riparian forests in the lower reaches of Tarim River as affected by air temperature at $10 \mathrm{~cm}$ above the ground surface and soil water. Acta Ecologica Sinica, 27(5): 1951-1959. (in Chinese)

Jasoni R L, Smith S D, Arnone III J A. 2005. Net ecosystem $\mathrm{CO}_{2}$ exchange in Mojave Desert shrub lands during the eighth year of exposure to elevated $\mathrm{CO}_{2}$. Global Change Biology, 11(5): 749-756.

Jenkinson D S, Adams D E, Wild A. 1991. Model estimates of $\mathrm{CO}_{2}$ emissions from soil in response to global warming. Nature, 351(6324): 304-306.

Jia X, Zha T S, Wu B, et al. 2013. Temperature response of soil respiration in a Chinese pine plantation: Hysteresis and seasonal vs. diel $Q_{10}$. PLoS ONE, 8(2): e57858, doi: 10.1371/journal.pone.0057858.

Jin Z, Qi Y C, Dong Y S. 2007. Diurnal and seasonal dynamics of soil respiration in desert shrubland of Artemisia ordosica on Ordos Plateau of Inner Mongolia, China. Journal of Forestry Research, 18(3): 231-235.

Jin Z, Qi Y C, Dong Y S, et al. 2009. Seasonal patterns of soil respiration in three types of communities along grass-desert shrub transition in Inner Mongolia, China. Advances in Atmospheric Sciences, 26(3): 503-512.

Li Y Q, Zhao H L, Zhao X Y, et al. 2008. Responses of soil respiration to air temperature from June to September in different sand dunes, Horqin sandy land. Journal of Desert Research, 28(2): 249-254. (in Chinese)

Liu Y H, Ali M, Yang F, et al. 2015. Environmental factors driving winter soil respiration in the hinterland of the Taklimakan Desert, China. Acta Ecologica Sinica, 35(20): 6711-6719. (in Chinese)

Lou Y Q, Zhou X H. 2006. Soil Respiration and the Environment. San Diego: Academic Press, Elsevier, 1-88.

Ma J, Wang Z Y, Stevenson B A, et al. 2013. An inorganic $\mathrm{CO}_{2}$ diffusion and dissolution process explains negative $\mathrm{CO}_{2}$ fluxes in saline/alkaline soils. Scientific Reports, 3(1): 2025, doi: 10.1038/srep02025.

Ma J, Liu R, Tang L S, et al. 2014. A downward $\mathrm{CO}_{2}$ flux seems to have nowhere to go. Biogeosciences, 11(22): 6251-6262.

Oechel W C, Vourlitis G L, Hastings S J, et al. 2000. Acclimation of ecosystem $\mathrm{CO}_{2}$ exchange in the Alaskan Arctic in response to decadal climate warming. Nature, 406(6799): 978-981.

Phillips C L, Nickerson N, Risk D, et al. 2011. Interpreting diel hysteresis between soil respiration and temperature. Global Change Biology, 17(1): 515-527.

Qi Y C, Dong Y S, Domroes M, et al. 2006. Comparison of $\mathrm{CO}_{2}$ effluxes and their driving factors between two temperate steppes in Inner Mongolia, China. Advances in Atmospheric Sciences, 23(5): 726-736.

Rustad L E, Huntington T G, Boone R D. 2000. Controls on soil respiration: Implications for climate change. Biogeochemistry, 48(1): $1-6$.

Schlesinger W H, Andrews J A. 2000. Soil respiration and the global carbon cycle. Biogeochemistry, 48(1): 7-20.

Sierra C A. 2012. Temperature sensitivity of organic matter decomposition in the Arrhenius equation: some theoretical considerations. Biogeochemistry, 108(1-3): 1-15.

Singh J S, Gupta S R. 1977. Plant decomposition and soil respiration in terrestrial ecosystems. The Botanical Review, 43(4): 449-528.

Sponseller R A. 2007. Precipitation pulses and soil $\mathrm{CO}_{2}$ flux in a Sonoran Desert ecosystem. Global Change Biology, 13(2): 426-436.

Stone R. 2008. Have desert researchers discovered a hidden loop in the carbon cycle? Science, 320(5882): 1409-1410.

Subke J A, Reichstein M, Tenhunen J D. 2003. Explaining temporal variation in soil $\mathrm{CO}_{2}$ efflux in a mature spruce forest in Southern Germany. Soil Biology and Biochemistry, 35(11): 1467-1483.

Thomas A D, Hoon S R. 2010. Carbon dioxide fluxes from biologically-crusted Kalahari Sands after simulated wetting. Journal of Arid Environments, 74(1): 131-139.

Wang B, Zha T S, Jia X, et al. 2013. Soil moisture modifies the response of soil respiration to temperature in a desert shrub ecosystem. Biogeosciences Discussions, 10(6): 9213-9242. 
Wang X Y, Li Y L, Zhao X Y, et al. 2012. Responses of soil respiration to different environment factors in semi-arid and arid areas. Acta Ecologica Sinica, 32(15): 4890-4901. (in Chinese)

Wang Z Y, Wang Y G, Xie J B, et al. 2013a. Differentiating the soil inorganic $\mathrm{CO}_{2}$ flux of saline and alkaline soils. Arid Land Geography, 36(4): 655-661. (in Chinese)

Wang Z Y, Xie J B, Wang Y G, et al. 2013b. Soil inorganic $\mathrm{CO}_{2}$ flux in relation to soil $\mathrm{pH}$ and electric conductivity in saline/alkaline soils. Chinese Journal of Ecology, 32(10): 2552-2558. (in Chinese)

Wohlfahrt G, Fenstermaker L F, Arnone III J A. 2008. Large annual net ecosystem $\mathrm{CO}_{2}$ uptake of a Mojave Desert ecosystem. Global Change Biology, 14(7): 1475-1487.

Xie J X, Li Y, Zhai C X, et al. 2009. $\mathrm{CO}_{2}$ absorption by alkaline soils and its implication to the global carbon cycle. Environmental Geology, 56(5): 953-961.

Yang F, Ali M, Yang X H, et al. 2015. Characteristics and affecting factors of soil respiration in the northern margin of the Taklimakan Desert. Journal of Desert Research, 35(1): 195-202. (in Chinese)

Zhang L H, Chen Y N, Li W H, et al. 2007. Soil carbon dioxide emission and affecting factors under Haloxylon ammodendron community in Junggar Basin. Journal of Desert Research, 27(2): 266-272. (in Chinese)

Zhang Z S, Dong X J, Xu B X, et al. 2015. Soil respiration sensitivities to water and temperature in a revegetated desert. Journal of Geophysical Research: Biogeosciences, 120(4): 773-787.

Zhao R, Li X J, Zhao Y, et al. 2015. $\mathrm{CO}_{2}$ efflux from two typies biologically crusted soil in response to simulated precipitation pulses in the Tengger Desert. Journal of Desert Research, 35(2): 393-399. (in Chinese)

Zhou P, Liu G B, Xue S. 2009. Review of soil respiration and the impact factors on grassland ecosystem. Acta Prataculturae Sinica, 18(2): 184-193. (in Chinese) 